\title{
Immediate impact of medical abortion on women's health and clients' satisfaction with medical abortion
}

Paudel $\mathbf{N}^{\mathbf{1}}$

'Lecturer, B.Sc. Nursing Programme, Kathmandu Medical College Teaching Hospital, Kathmandu, Nepal

\section{Abstract}

Background: Medical abortion has been proved to be effective method for safe abortion. It is highly acceptable to women in a variety of settings, including where resources are limited.

Objective: The objective of the study was to assess the immediate impact of medical abortion on women's health and clients' satisfaction with medical abortion.

Methods: A descriptive study was conducted at Marie Stopes Center, Satdobato, Lalitpur. A total of 100 consecutive women visiting the center for medical abortion during 2010 September to 2010 October were included. Respondents were the women attending follow up visit following medical abortion using Mifepristone $200 \mathrm{mg}$ orally followed by Misoprostol $800 \mu \mathrm{g}$ per vaginal after 24 hours of oral Mifepristone. Structured questionnaire was designed and interview method was used for data collection. Statistical Package for Social Sciences version 16 was used to analyze the data.

Results: The success rate of medical abortion was $91 \%$. Most of the respondents did not have any problems besides the expected effects and side effects of the method such as bleeding, abdominal cramping, nausea, vomiting, dizziness and headache. Majority (79\%) of respondentswas satisfied with medical abortion and $76 \%$ respondents said they would recommend this method to others in future. There was no significant relationship between information and counseling and client's satisfaction with medical abortion.

Conclusions: The immediate impact of medical abortion on women's health is positive. It is a safe and easy method in termination of early pregnancy and most of the clients were satisfied with this method.

Key words: Clients' satisfaction, Immediate impact, Medical Abortion

\section{INTRODUCTION}

A bortion is the termination of a pregnancy before the foetus has attained viability, i.e. become capable of independent survival in extra-uterine life'. "Safe abortion service" refers to termination of unwanted pregnancies through safe technique with effective pain management; post procedure family planning information and service are being provided to avoid further unwanted pregnancies. "Comprehensive abortion care" services include examination by the trained doctor or health worker, counselling on abortion and family planning options and services, abortion service using Manual Vacuum Aspiration (MVA) or Medical abortion (MA) or other methods, effective pain management and other reproductive health services if needed". "Medical abortion" (MA) involves the use of pharmacologic

\footnotetext{
Address for correspondence

Narayani Paudel

Lecturer, B.Sc. Nursing Programme

Kathmandu Medical College Teaching Hospital

Sinamangal, Kathmandu

E-mail: paudelgn@gmail.com
}

agents, such as Mifepristone and Misoprostol, to expel the products of conception. Used together, these medications stimulate uterine contractions and cause expulsion of the products of conception ${ }^{3}$.

Globally, complications after unsafe abortion cause 13\% of maternal deaths. Every year 42 million abortions are estimated to take place, 22 million safely and 20 million unsafely. Unsafe abortion accounts for 68,000 maternal deaths each year and causes a further five million women to suffer temporary or permanent disability. Each year, about one half of the estimated 68,000 unsafe abortionrelated deaths occur in Asia. The unsafe abortion rate is higher in the poorer countries of South-central and South-East Asia than in the wealthier countries of East Asia, such as Japan and South Korea. In South-central and Southeast Asia, the unsafe abortion rate is about 20 per 1,000 women of reproductive age. Medical abortion accounts for about $10 \%$ of total abortions in the United States and Europe 4 . 
Manual Vacuum Aspiration (MVA) is the main procedure used for safe abortion in Nepal. Medical Abortion using Mifepristone and Misoprostol is a safe, cost-effective and acceptable option for terminating pregnancies. Millions of women throughout the world have chosen MA. Many women feel it is more private and acceptable than other methods. The government of Nepal had officially introduced MA in the fiscal year 2065/066 (2009 AD) in six districts (Jhapa, Dhading, Chitawan, Tanahun, Surkhet and Kailali) on a pilot basis. Recently, it is being scaled up to rural and remote health facilities as well ${ }^{2,3}$. Prostaglandins (PGs) became available since early 1970s and anti-progesterone since 1980s. Since then medical abortion has become an alternative method of first trimester termination of pregnancy. The most widely used regime is Mifepristone with Misoprostol ${ }^{5}$.

Nepal is a developing country committed to provide basic health services within the country. Reproductive care services is lacking in many places. That is why Nepal has one of the highest Maternal Mortality Ratios (MMR) (281/10,000 live births) in Asia, a high unmet need for contraception of $24.6 \%$ and low contraceptive prevalence rate of $44 \%{ }^{6}$. In 2002, Nepal changed its civil code to legally permit abortion, largely in response to deaths and injuries from unsafe abortion. The first comprehensive abortion care service was offered in Kathmandu, in 2004 and now comprehensive abortion care is available in all 75 districts throughout the country ${ }^{7}$. Despite remarkable progress and the availability of legal and safe abortion services, unsafe abortion remains an issue. Safe abortion services are mainly confined to cities and district headquarters, so women in rural and remote areas face myriad barriers - physical, informational and financial. According to the Nepal Maternal Mortality and Morbidity Study 2008/09, abortion (induced and spontaneous) is the third highest direct cause of maternal mortality, constituting nearly 14 per cent of hospital deaths ${ }^{8}$. In low resource settings and where access to other safe abortion methods is limited, MA has the potential to dramatically reduce maternal morbidity and mortality. In 2007, WHO added Mifepristone and Misoprostol for abortion to its Model List of Essential Medicines 9 . The Government of Nepal also is planning to add these medicines in essential drug list ${ }^{3}$. However medical abortion method has been proved as effective method for safe abortion; there is need for further study regarding impact on health and clients' satisfaction of this method. Hence this study was undertaken in order to assess the immediate impact of medical abortion on women's health and clients' satisfaction with medical abortion.

\section{METHODS}

A descriptive research design was used to identify the immediate physical and psycho-social impact of medical abortion on women's health and clients' satisfaction with medical abortion. Marie Stopes Services of Satdobato, Lalitpur, Nepal was the research setting. All the women attending for follow-up visit at Marie Stopes clinic within two to three weeks following medical abortion (with Mifepristone $200 \mathrm{mg}$ orally followed by Misoprostol 800 $\mu \mathrm{g}$ per vaginal after 24 hours of oral Mifepristone) were the research population. Medical abortion users were having less than nine weeks of pregnancy. Sample size was one hundred (100) and non-probability consecutive sampling technique was adopted for data collection. Women seeking safe abortion service but using other than medical method and those not attending followup within three weeks following medical abortion were excluded from the study.

Structured questionnaire was designed for data collection. Pre-testing was done in $10 \%$ of total sample and that sample was excluded in the real study. Necessary modification in the questionnaire was done after analysing the pre-testing data and finalisation of questionnaire was done. Research advisors as well as experts of research, statistics and language were consulted to measure the validity and reliability of the instrument.

Permission from authority i.e. central office of Sunaulo Parivar Nepal was taken for data collection. The required data were collected within the period of four weeks, from fifth September 2010 to sixth October 2010 by the researcher herself through interview technique. Around 30 minutes was consumed for each interview. Participants of the study were fully informed about the nature of the study, the research objectives, and the confidentiality of data. Separate room was used for interview and individual interview was done to maintain privacy. Exit interview was done and comfortable environment was created for getting reliable and adequate information. The outcome of method was labelled as successful when the result of urine test for pregnancy (UPT) was negative after two weeks of medical abortion.

Data was entered in the same day of collection to avoid any omissions. Coding and editing of data was done as necessary. Collected data were analysed using Statistical Package for the Social Sciences (SPSS, 16.0 version). Both descriptive and inferential statistics were used for the analysis of data. The findings of the study were reported in frequency and percentage. 


\section{RESULT}

The demographic characteristics of the participants are presented in Table 1. Majority (82\%) of respondents were of the age group of 20 to 35 years with mean age of 27.75 years and standard deviation of 5.296 years. Majority of respondents were educated up to school level and master's degree has been received by very few women. According to occupation, majority (51\%) of respondents were house-wives. On the basis of marital status, most $(90 \%)$ of the respondents were married. On the basis of number of pregnancy, majority (55\%) of respondents had three or more pregnancies. According to number of children, the higher proportion of respondents (39\%) had one child.

Regarding the potential side effects of medical abortion, $41 \%$ respondents had no complaints, $35 \%$ respondents felt nausea, nine per cent had vomiting, eight percent had dizziness and seven percent complained headache after taking abortion pills (Table 2). Most (91\%) of the respondents had no complications. No respondents reported that they had psychological or family problems following medical abortion. The success rate of medical abortion was $91 \%$. Remaining nine percent clients had incomplete abortion and had to undergo surgical evacuation. Manual vacuum aspiration was done by doctor (Table 3).

Most (90\%) of the respondents were satisfied with information provided by health workers regarding medical abortion and $10 \%$ were not. Majority (79\%) of the respondents were satisfied with medical abortion but $21 \%$ respondents were not satisfied with the method. Among 21 respondents who were not satisfied, the main cause of dissatisfaction was long term bleeding; more than two weeks in 16 (76\%). Three (14\%) respondents found it doubtful and two (9.52\%) respondents were dissatisfied with medical abortion because of severe abdominal pain and bleeding. Majority (76\%) of respondents said they would recommend medical abortion to others in future (Table 4).

There was no significant association between sociodemographical variables such as age, educational status, occupation, parity and immediate impact of medical abortion and clients' satisfaction. Likewise satisfaction rate of the method was not associated with information and counselling provided by the health workers.
Table 1: Socio-demographic Characteristics of the Respondents

\begin{tabular}{|c|c|}
\hline Variables & $\begin{array}{c}\mathrm{n}=100 \\
\text { Percentage (\%) }\end{array}$ \\
\hline \multicolumn{2}{|l|}{ Age (In years) } \\
\hline Below 20 & 5.0 \\
\hline $20-25$ & 21.0 \\
\hline $25-30$ & 37.0 \\
\hline $30-35$ & 24.0 \\
\hline $35-40$ & 13.0 \\
\hline \multicolumn{2}{|l|}{ Education Level } \\
\hline Illiterate & 11.0 \\
\hline Literate & 89.0 \\
\hline Primary level & 17.0 \\
\hline Secondary level & 29.0 \\
\hline Intermediate level & 22.0 \\
\hline Bachelor level & 17.0 \\
\hline Masters level & 4.0 \\
\hline \multicolumn{2}{|l|}{ Main occupation } \\
\hline House Wife & 51.0 \\
\hline Service & 22.0 \\
\hline Student & 14.0 \\
\hline Daily wages & 7.0 \\
\hline Business & 6.0 \\
\hline \multicolumn{2}{|l|}{ Marital Status } \\
\hline Married & 90.0 \\
\hline Unmarried & 10.0 \\
\hline \multicolumn{2}{|l|}{ Number of pregnancy } \\
\hline One & 17.0 \\
\hline Two & 28.0 \\
\hline Three & 28.0 \\
\hline Four and more & 27.0 \\
\hline \multicolumn{2}{|l|}{ Number of children } \\
\hline None & 24.0 \\
\hline One & 39.0 \\
\hline Two & 27.0 \\
\hline Three and more & 10.0 \\
\hline
\end{tabular}

Table 2: Distribution according to Side Effects of Medical Abortion

\begin{tabular}{|cc|}
\hline Side effects occurred & $\mathbf{n}=\mathbf{1 0 0}$ \\
None & Percentage (\%) \\
\hline Nauses & 41.0 \\
Vomiting & 35.0 \\
Dizziness & 9.0 \\
Headache & 8.0 \\
\hline
\end{tabular}


Table 3: Distribution of Respondents According to Outcome of Medical Abortion

\begin{tabular}{lc}
\multicolumn{1}{c}{ Variables } & $\begin{array}{c}\mathbf{n}=\mathbf{1 0 0} \\
\text { Percentage (\%) }\end{array}$ \\
Outcome of MA & \\
\hline Success (Complete abortion) & 91.0 \\
$\quad$ Long-term bleeding (Incomplete) & 9.0 \\
\hline Further treatment needed & \\
\hline None & 91.0 \\
\hline Manual Vacuum Aspiration (MVA) & 9.0 \\
\hline
\end{tabular}

Table 4: Clients' Satisfaction with Information and Counseling and MA

\begin{tabular}{lc}
\hline Variables & $\mathbf{n}=\mathbf{1 0 0}$ \\
Percentage (\%)
\end{tabular}

\section{DISCUSSION}

This study showed that there was no adverse immediate impact of medical abortion on women's health except the expected effects and potential side effects of the method. All respondents had experienced bleeding and varying degree of abdominal pain. The main side effects were nausea, vomiting, dizziness and headache. Studies have concluded that many of the side effects of medical abortion are expected and generally minor. During the course of a medical abortion, nearly all women experience pain resulting from uterine cramping, and bleeding, often with passage of clots. Nausea, vomiting, and diarrhoea are frequent side effects ${ }^{10}$. Side effects were somehow different in a study on MA among 50 pregnant women with amenorrhea of 49 days or less in which the most common side effects with the combined use of Mifepristone and oral Misoprostol were weakness 24 (48\%), nausea $10(20 \%)$, diarrhea $12(25 \%)$, needed analgesics $4(8 \%)^{11}$.

Combined regimens using Mifepristone and Misoprostol through nine weeks since the woman's last menstrual period have been widely studied and safely used by millions of women in many countries. Research protocols for pregnancies up to nine weeks since woman's last menstrual period report success rates up to 98 percent ${ }^{10}$. Numerous studies have now overwhelmingly demonstrated the efficacy and safety of the Mifepristone and Misoprostol regimen. Approximately $95 \%$ of women will have a successful abortion when using Mifepristone/ Misoprostol within 49 days from the onset of the last menstrual period. Medical abortion completions rates appear higher at earlier gestational ages ${ }^{10}$. But the findings of the study revealed slightly lower success rate i.e. $91 \%$. A slightly higher success rate $(94 \%)$ has been shown in a study conducted in Norvic International Clinic $^{11}$. However, the findings were consistent with a study in which it was concluded that most $(91.3 \%)$ of the 367 women with known outcomes had successful medical abortions ${ }^{12}$.

The findings of the study suggested that majority of respondents (79\%) were satisfied with medical abortion and $76 \%$ of respondents would recommend medical abortion to others in future. In contrast, 98\% clients were satisfied in the study done in Norvic International Clinic $^{11}$. Likewise, studies consistently show that 85 to 95 per cent of women are satisfied or highly satisfied with the method, and would be willing to use it again or recommend it to a friend if needed ${ }^{12,13}$.

The respondents who were satisfied with medical abortion had reported that the method was easy, more private and non-surgical. The finding was consistent with comparative studies between medical abortion and surgical abortion in which it was shown that women who choose MA are more satisfied with it than those who are randomly assigned other method. The non-invasive aspect of $M A$, as opposed to a vacuum aspiration procedure, is often mentioned as a significant benefit. Some women perceive MA as a more private and natural method. Women may take the medications at home, which gives them more control over the conditions under which they have the abortion ${ }^{14,15}$.

The study was limited to a small sample and the respondents for the study were selected by using purposive sampling technique. So the results of the study cannot be generalized to entire population. Being a sensitive issue, the information provided by the respondents may have been under-reported.

A large scale study can be conducted in the same area of research. Comparative study can be done to find out clients' satisfaction between medical and surgical abortion. The study on remote (long-term) impact of medical abortion on women's health can be done in future. 


\section{CONCLUSION}

Medical abortion is safe, effective, easy and private method in termination of early pregnancy. The outcome of method is good and the immediate impact of medical abortion on women' health is positive. Most of the clients are satisfied with this method and they will recommend this method to others in future.

\section{REFERENCES}

1. World Health Organization. Reproductive Health Indicators: Guidelines for their generation, interpretation and analysis for global monitoring [Internet]. Geneva:World Health Organization, 2006; (cited 2010 Jul 16) p. 48. Available from: whqlibdoc. who.int/publications/2006/924156315X_eng.pdf

2. Department of Health Services. Annual Report 2008/09. Kathmandu: Government of Nepal Ministry of Health and Population: 2010. p. 92-93.

3. Government of Nepal, Ministry of Health and Population, Department of Health Services, Family Health Division. Medical abortion reference manual. National Training Center, Kathmandu, 2009: 2-3.

4. Alan Guttmacher Institute. Sharing Responsibility, Women Society and Abortion Worldwide [Internet]. New York; 2009. Available from: http://www. gutmacher.org

5. Kulier R, Gulmezoglu AM, Hofmeyr GJ, Cheng LN, Campana A. Medical methods for first Trimester abortion [Internet]. Cochrane Database Syst. Rev. 2004;(1):CD002855. Review. Update in Cochrane Database Syst. Rev. 2004;(2)CD002855 PMID:14973995; (cited 2010 Jul 20). Available from: http://www.ncbi.nlm.nih.gov/pubmed/155106180

6. Ministry of Health and Population. Nepal Demographic and Health Survey 2006. Family Health Division, New ERA, ORC Marco: Kathmandu; 2007.

7. Network for Addressing Women's Reproductive Rights in Nepal (NAWRN). Increasing Awareness and Access to Safe Abortion among Nepalese Women. Kathmandu: Center for Research on Environment Health and Population Activities (CREHPA); 2009.

8. Subedi BK, Pradhan A, Basnet S, Puri M, Rai S, Poudel $P$, et al. Nepal Mortality and Morbidity
Study 2008/2009: Summary of preliminary findings [Internet]. Kathmandu: Family Health Division, Department of Health Services, Ministry of Health, Government of Nepal; 2009 (cited 2010 Jul 26). p. 5-6.Available from: http:///www.dfid.gov.uk/ documents/publications/Nepal-maternal mortality pdf

9. World Health Organization (WHO). WHO model list of essential medicines. 15th ed. Geneva: WHO; 2007.

10. National Abortion Federation. Expected side effects of medical Abortion. Washington DC: National Abortion Federation 2010. (cited 2010 Jul 20). Available from: http://www.prochoice.org/ education/cme/online_cme/m2expected2.asp

11. Shrivastava V, Shrivastava A. Mifeprostone and Oral Misoprostol for early medical Abortion. J Nepal Health Res Counc. 2009 Oct;7(2):127-30.

12. Karki C, Pokharel H, Kushwaha A, Manandhar D, Bracken $\mathrm{H}$, Winikoff B. Acceptability and feasibility of medical abortion in Nepal. Int J Gynaecol Obstet. 2009 Jul;106(1):39-42.

13. Winikoff B, Irning S, Kurus C, Evlio C, Xiao B, Gu S, et al. Safety, efficacy and acceptability of medical abortion in China, Cuba and India: A comparative trial of Mifepriostone- Misoprostol versus surgical abortion. Am J Obstet Gynecol. 1997;176(2):431-7.

14. Winikoff B. Acceptability of medical abortion in early pregnancy. Family planning perspectives. 1995 Jul-Aug;27(4):142-8, 185. (cited 2010 Jul 16). Available from: http://www.guttmacher.org/pubs/ journals/2714295.html

15. Henshaw RC, Naji SA, Russell IT, Templeton AA. Comparison of medical abortion with surgical vacuum aspiration: women's preferences and acceptability of treatment. BMJ. 1993;307(6906):714-7. 